\title{
EL PERONISMO Y LA HISTORIOGRAFÍA: UNA DISPUTA EN TORNO A SU INTERPRETACIÓN
}

\author{
María José Malet
}

\section{INTRODUCCIÓN}

Sin lugar a dudas, el peronismo constituye uno de los temas más conflictivos de la historia argentina, generando aún hoy posiciones contrarias y acalorados debates. En un país cuya cultura política tiende a convertir las discusiones en enfrentamientos maniqueos, es imposible dejar de lado al peronismo como una de las contrapartes. Asimismo, se trata de uno de los períodos más estudiados de la historia argentina. Los investigadores sociales unánimemente coinciden en sostener que resulta indispensable comprender el peronismo para alcanzar un conocimiento cabal del siglo XX en el país. Constituye un punto de inflexión fundamental, determinando un antes y un después la aparición en la escena pública de Juan Domingo Perón y cuya ausencia o presencia se convirtió en clave para descifrar el devenir histórico nacional.

En el siguiente trabajo, se brindará un estado de la cuestión sobre las diversas interpretaciones de las que ha sido objeto el peronismo, cuestión que en los últimos años ha sido relegada a un segundo plano, virando el interés hacia estudios y análisis de aspectos reducidos y acotados, generalmente de la periferia, que deben ser vistos en conjunto para adquirir una perspectiva global. Finalmente, se intentará realizar una aportación a tan importante cuestión.

Antes de dar inicio al trabajo, nos vemos obligados a realizar algunas especificaciones terminológicas. En primer lugar, se debe distinguir entre dos conceptos distintos: peronismo y justicialismo, empleados muchas veces como sinónimos. Mientras el primero se refiere a un movimiento encabezado por Perón y a su gobierno entre 1946y $1955^{1}$; justicialismo hace alusión, por un lado, al partido político justicialista y, por otro, a la adopción de parte de la

1. Muchos autores toman como fecha de inicio del fenómeno peronista a 1943, año en que Perón asume el Departamento Nacional del Trabajo, a partir del cual irá escalando en la jerarquía gubernamental hasta 1945, en que concentrará en sus manos la Vicepresidencia, el Ministerio de 
doctrina peronista como fundamento ideológico del partido. En segundo lugar, corresponde definir qué entendemos por peronismo, dentro del cual se funden régimen, movimiento, partido e ideología. El peronismo nace como movimiento, conforma un partido político, se constituye como régimen entre 1946 y 1955 y se conduce siguiendo una ideología. Y todo ello alrededor de una sola figura: Juan Domingo Perón. A continuación, no reduciremos el término peronismo a una acepción, sino que lo emplearemos en un sentido amplio, abarcativo tanto del régimen, del partido, el movimiento y la ideología. Consideramos más beneficioso esta concepción amplia, que una visión reduccionista, que nos conduce a interminables laberintos, al mismo tiempo que brinda la posibilidad de considerar sus diversos componentes.

\section{LA HISTORIOGRAFÍA PERONISTA}

De diversas interpretaciones ha sido objeto el peronismo atendiendo a la corriente historiográfica que adscribe cada estudioso, a su postura política, o a los factores que consideran claves. Resulta evidente que buena parte de los historiadores, sociólogos, economistas, politólogos e, incluso, políticos, se han visto seducidos por el peronismo y han escrito sobre él. A pesar de ello, muchos aspectos todavía necesitan un estudio más profundo, sobre todo los historiográficos. Se puede mencionar los trabajos de Mariano Ben Plotkin ${ }^{2}$ donde lleva a cabo un repaso bibliográfico sobre el peronismo, y el de César Tcach ${ }^{3}$, quien repasa las distintas interpretaciones sobre el origen del movimiento peronista.

\section{Visión bonapartista y bismarckista}

Comenzaremos con dos interpretaciones que han tenido poco éxito: la de bonapartismo y bismarckismo, sostenidas por socialistas y marxistas generalmente. Los investigadores que destacan el papel desempeñado por el Estado en el proceso de industrialización, observan características del Gobierno de Bismarck; aquellos que hacen hincapié en el rol del líder como árbitro en las relaciones sociales, lo entienden bonapartista. En tanto la conciliación entre las clases sociales es imposible de alcanzar, el arbitraje se convierte en el instrumento que permite mantener las relaciones de dominación tradicionales. De tal forma, Osvaldo Calello afirma «las condiciones estuvieron dadas para el surgimiento de una jefatura que con el aparato estatal como soporte y el apoyo de las grandes masas obreras y populares, ganase autonomía respecto de las clases sociales para llevar adelante la politica que la burguesía nacional no se animaba a encarar. Tal el carácter

Guerra y el Ministerio de Trabajo y Previsión. Un año más tarde asumía como Presidente de la Nación, siendo derrocado por un golpe militar en 1955.

2. Plotkin, Mariano Ben, "Perón y el peronismo: un ensayo bibliográfico», EIAL, vol. 2, n. ${ }^{\circ}$ 1, enero-junio 1991.

3. TCACH, César, "El enigma peronista. La lucha por su interpretación», Historia Social, n. ${ }^{\circ} 43$, parte II, 2002, pp. 129-139. 
bonapartista que adquirió la jefatura de Perón»»". Naturaleza bonapartista que se ve profundizada al hegemonizar diversas y contrarias identidades de clase, desde la clase obrera, nacionalistas, industriales y anti-imperialistas, cualidad que explica el movimiento pendular del líder en sus medidas y discursos.

\section{Visión fascista}

La visión del peronismo como nazi-fascista surge a la par que el peronismo, alentado de sobremanera por la polarización ideológica internacional, utilizada hábilmente por Perón en su enfrentamiento con Braden ${ }^{5}$. Se trata de una interpretación que predominó en las décadas de 1940 y 1950 y que resurge hacia 1980. Así lo van a entender estudiosos de diversas corrientes: liberales, socialistas y comunistas. En este camino, el historiador y ministro de la Corte Suprema de Justicia, Carlos Fayt ${ }^{6}$, realiza una analogía entre los regímenes europeos y el argentino, advirtiendo las siguientes similitudes: la acción precede a la doctrina; los valores defendidos de orden, jerarquía y disciplina; la negación del liberalismo y el marxismo; la concepción del movimiento y del Estado como voluntad única del líder; el corporativismo; la concepción expansiva del Estado acompañada de una subordinación del individuo a él, transformándose de ciudadano en creyente por el culto al líder; la apelación a la acción directa y el consecuente desprecio por la democracia y el pluralismo político. Esta concepción es fuertemente discutida, sobre todo por José Miguens ${ }^{7}$, quien sostiene el origen antiperonista de la vía interpretativa, la confusión por parte de los estudiosos con la personalidad autoritaria y el fascismo, y que en el peronismo no aparecen los principales aspectos claves del fascismo: por un lado, las clases medias no se sienten amenazadas por el avance de la clase trabajadora; los terratenientes y grandes empresarios no apoyan al nuevo líder; las estructuras no tienen modelos militaristas, es decir, una organización jerárquica y disciplinada con una milicia destinada a eliminar a los competidores; y por último, mientras los fascismos europeos son expansionistas e imperialistas, los nacionalismos lati-

4. Calello, Osvaldo, "Perón, los trabajadores y la izquierda", Izquierda Nacional / Historia, 20 de febrero de 2006, pp. 1-28, p. 2. La revista pertenece al grupo Socialismo Latinoamericano. Disponible en: http://www.izquierdanacional.org/historia/pdfs/h001.pdf (25-04-2007). Más tarde agrega: «Su bonapartismo fue el resultado de una contradicción sobredeterminada, estructurada en torno a dos ejes principales: el de la contradicción de contenido nacional del viejo país dependiente de la década del 40, y el eje del antagonismo de clase de una sociedad capitalista. La necesidad de construir un discurso antioligárquico pero a la vez burgués; antiimperialista pero al mismo tiempo encuadrado en los límites del capitalismo, determinó una particular configuración ideológica», p. 3.

5. En vísperas a las elecciones de 1946, la Embajada norteamericana publicó y distribuyó el denominado Libro Azul, donde acusa a diversos militares argentinos de estar vinculados a los regímenes nazi-fascistas europeos. Ante esto, Perón propuso una elección dicotómica: «Braden o Perón», asociando al embajador norteamericano a los intereses foráneos que sólo buscan aumentar sus beneficios en detrimento del bienestar nacional.

6. Citado en Del BARCO, Ricardo, El régimen peronista: 1946-1955, Buenos Aires, Belgrano, 1983, p. 18.

7. Miguens, José Enrique, «Actualización de la identidad justicialista», en Miguens, José Enrique y TURNER, Frederick C., Racionalidad del peronismo, Buenos Aires, Planeta, 1988, pp. 1-52. 
noamericanos son defensivos de los imperialismos de los países centrales. Estos puntos han sido estudiados por otros historiadores y han llegado a conclusiones opuestas, aunque no por ello llegan a acusar al peronismo de fascista, aunque sí establecen fuertes vínculos entre ambos, como veremos más adelante. No se puede decir que la alta burguesía argentina haya apoyado unánimemente a Perón, pero es indudable que confiaron en él para que el creciente movimiento obrero y popular no se fuera de sus cauces, o al menos, lo que ellos consideraban tolerable. Es en este sentido que se entiende la tan conocida frase de Perón "De casa al trabajo y del trabajo a casa». El general no pretendía romper con las relaciones capitalistas de producción, sino afianzarlas y mantenerlas de forma estable. Así, Perón mitigaba el temor de las clases medias ante los obreros, al tiempo que conquistaba el apoyo de ambos sectores. En relación a los modelos militaristas, veremos más adelante la clara influencia fascista que tuvo sobre Perón y su concepción de cómo debía organizarse la sociedad, el Estado, y el Partido Peronista.

En el camino de sostener al peronismo con inclinaciones fascistas, aunque sin calificarlo abiertamente como tal, encontramos a Carlos Malamud, que observa manifestaciones profacistas ${ }^{8}$ en el régimen, y a Paul Lewis ${ }^{9}$, historiador estadounidense que en un primer momento observa un peronismo populista, que una vez en el Gobierno se orientó hacia la construcción de un Estado corporativo, aunque no lo consiguió. Al igual que el modelo italiano, el Estado sindicalista se justificó en la ideología peronista, que no era más que una reformulación de la idea de «la nación en armas». El estudio de Fermín Chávez coincide con Lewis en su análisis sobre las fuentes del pensamiento peronista y nos recuerda que Perón formó parte de una elite militar local desde sus jóvenes inicios en la Escuela Superior de Guerra, donde estuvo influenciado por el coronel Bartolomé Descalzo y el coronel Juan Lucio Cernadas. Posteriormente, se debe incorporar la ascendencia del ministro de Guerra, Manuel E. Rodríguez, cuando pasa a desempeñarse bajo su mando. El viaje del futuro presidente argentino como agregado militar por Italia y Alemania, que menciona sucintamente el autor, le permite entrar en contacto directo con las experiencias fascistas y con los textos de Colmar von der Goltz y Clausewitz, que luego serán complementados con las obras de Manuel Ugarte, del general Alfonso Baldrich, Leopoldo Lugones, Alejandro Bunge y Carlos Ibarguren. La obra del mismo Perón, Apuntes de Historia Militar, publicada por primera vez en 1932, da buena cuenta de aquellas ascendencias y algo más: "Es de carácter militar, pero es aplicable a la politica» ${ }^{10}$. Así Perón trasladó conceptos militares al ámbito político: táctica, estrategia, nación en armas que fue transformado en pueblo en armas. Al convertir a la doctrina

8. Malamud, Carlos D., "El populismo en Latinoamérica», Cuadernos del Mundo Actual, n. ${ }^{\circ} 76$, Madrid, Historia 16, 1994, p. 24.

9. LeWIS, Paul, La crisis del capitalismo argentino, Buenos Aires, Fondo de Cultura Económica, 1993, capítulo 8.

10. Juan Domingo Perón en FeInmann, Pablo, La sangre derramada. Ensayo sobre la violencia política, Buenos Aires, Ariel, 1998, p. 38. 
peronista en nacional, la sociedad quedó dividida en dos, tal y como sucede en la guerra. Como señala Pablo Feinmann, «trasladar conceptos militares a la política implica considerar a la política desde el punto de vista de la guerra; es, en suma, transformar la política en guerra» ${ }^{11}$.

En la misma vía interpretativa, Francisco Martínez Hoyos sostiene el peronismo como populista, autoritario y simpatizante del fascismo ${ }^{12}$, evidenciable en la alianza Franco-Perón. Alianza que no sólo se reduce a las carnes y cereales que la Argentina vende a España, al tiempo que le otorga créditos para que pagara esos envíos. El país latinoamericano también se comprometió a defender a su Madre Patria en los ámbitos internacionales. Raanan Rein es uno de los principales historiadores que se ha dedicado al estudio de esta alianza, cuya justificación, siguiéndolo, no debe reducirse a las necesidades económicas derivadas del debilitamiento en los vínculos comerciales con Gran Bretaña, sino que también debe tenerse en cuenta «el deseo del régimen de apaciguar a sus partidarios nacionalistas de la derecha; la simpatía de Perón hacia un régimen fuerte y anticomunista encabezado por un militar; y los esfuerzos por modelar una nueva conciencia nacional de la cual la Hispanidad era un componente básico» ${ }^{13}$. La afinidad entre Franco y Perón no sólo se observa en los estrechos lazos comerciales, políticos y diplomáticos, sino también en que la España franquista fuera el destino elegido por el mandatario argentino para vivir su destierro. Un asilo que duró trece años no puede ser reducido a un "deber moral» por parte de España ${ }^{14}$ en agradecimiento a la ayuda brindada en el pasado, sino que es signo de una alianza que iba más allá de las circunstancias del momento.

Raanan Rein afirma a la política exterior y al posicionamiento internacional de los países como factores explicativos de la alianza entre 1946 y 1950 y su posterior alejamiento. Pero el asilo brindado al General no alcanza a ser comprendido si no tenemos en cuenta la afinidad de estos dos militares, anticomunistas, antiliberales, nacionalistas y autoritarios. Porque los beneficios que obtuvo el régimen franquista con los envíos de alimentos y los préstamos con promesa de no ser cobrados con prontitud, son fácilmente evidenciables, pero no resultan tan evidentes las ventajas que pudo obtener el régimen franquista alojando a Perón desde 1960 a 1973.

11. Loc. cit.

12. Martínez Hoyos, Francisco, «Peronismo. El populismo en Argentina», Historia y Vida, n. ${ }^{\circ} 424$ (2003), pp. 16-20.

13. ReIN, Raanan, «El pacto Franco-Perón: justificación ideológica y nacionalismo en Argentina», EIAL, vol. 1, n. ${ }^{\circ} 1$, enero-junio 1990 , p. 2 . El cambio en el discurso peronista del término Hispanidad por Latinidad, ocurrido hacia 1950, es estudiado por ReIN, Raanan en «Hispanidad y oportunismo político: el caso peronista», EIAL, vol. 2, n. ${ }^{\circ} 2$, julio-diciembre 1991, donde plantea un intento fallido por parte del presidente argentino en su búsqueda por conformar una conciencia nacional y popular. Ante tal fracaso, Perón buscó una alternativa "dentro del repertorio cultural de posibles identidades que estaba a su disposición», escogiendo finalmente la latinidad. Para un estudio más profundo de la relación Franco-Perón, se puede consultar la tesis doctoral del mismo autor, La salvación de una dictadura. Alianza Franco-Perón, 1946-1955, Madrid, Consejo Superior de Investigaciones Científicas, 1995.

14. ReIN, Raanan, La salvación de una dictadura..., p. 264. 
Seguramente, el historiador que mejor ha defendido la tesis fascista es Tulio Halperín Dongui. En Argentina en el callejón ${ }^{15}$, recopilación de cinco escritos publicados entre 1955 y 1963, donde analiza el conflictivo período que va del Gobierno peronista a la Revolución Argentina, profesándole poca simpatía al peronismo y refiriéndose hacia él en los términos de régimen, dictadura o gobierno militar. Se debe tener en cuenta que el período formativo del historiador coincidió con el Gobierno peronista, de tal forma que su valoración proviene tanto de su experiencia vital como de su estudio y análisis.

Al examinar los puntos de encuentro entre la ideología peronista y la fascista, el autor concluye que el peronismo no fue una forma de fascismo, sino que "fue por lo menos el resultado -o más bien el residuo, inesperado para todos y también para su creador y beneficiario- de una tentativa de reforma fascista de la vida politica argentina» ${ }^{16}$, surgida en el preciso momento en que "mientras la Argentina parecía madura para el fascismo, el mundo se revelaba demasiado maduro para él» ${ }^{17}$. A lo largo de su período formativo, Perón había hecho suyas las ideas fascistas, pero una vez en el Gobierno se dio cuenta de la imposibilidad de llevarlas a cabo y debió buscar medios más conciliadores con la situación que atravesaba el país. Así es que el peronismo adquiere esos rasgos tan particulares pero que no alcanzan a explicar la manera en que logró mantenerse en el poder durante un decenio. Siguiendo a Halperín Donghi, su permanencia fue posible merced al apoyo de una inmadura clase trabajadora, cualidad que fue mantenida por Perón en tanto le permitía un mejor control de la masa obrera; de la resistencia, sector que se oponía al Gobierno de la restauración conservadora; y de los nuevos industriales que acuñaron importantes fortunas bajo la sustitución de productos manufacturados que se desarrolló en la década anterior. Como señala el historiador, la obtención de apoyo por parte de grupos con intereses tan distintos $y$, en muchas ocasiones opuestos, fue posible recurriendo a la manipulación, fundamentalmente de los sectores populares. El carácter de apoyo popular incondicional que muchos le adjudican al peronismo es totalmente cuestionado al afirmar que «las escenas de cólera popular debieron ser preparadas no sólo en cuanto a las incitaciones iniciales sino en todo su curso» ${ }^{18}$. A ello debemos agregar los discursos preparados para cada ocasión de acuerdo al público al que iban destinados, y que consecuentemente se contradecían entre ellos; las medidas populistas y demagógicas; pero también las atrocidades que se cometían en «el secreto de las comisarías ${ }^{19}$, olvidadas ante las bárbaras políticas represivas practicadas por el Estado argentino posteriormente.

Así, el peronismo se convierte en un intento por fascistizar la vida argentina, bajo un "talante de romería», con un tono carnavalesco y con una cualidad fundamental: "mostraba una dependencia del jefe y del estado que no era sino la confir-

15. Halperín DONGHI, Tulio, Argentina en el callejón, Buenos Aires, Ariel, 1995.

16. Ibidem, p. 29.

17. Ibidem, p. 35 .

18. Ibidem, p. 46.

19. Loc. cit. 
mación de que en él mantenían vigencia rasgos más antiguos y duraderos de nuestra vida política» ${ }^{20}$. La "revolución peronista» mantuvo aquellos rasgos tradicionales de la cultura política argentina que lo acercaban a los grupos con poder económico y social que previamente habían conducido al país, al tiempo que incorporaba a las masas populares como instrumento de legitimación y poder. El prestigioso historiador José Luis Romero, identificó de la misma forma al fenómeno peronista, es decir, como un «régimen personalista, autoritario y encubiertamente fascista ${ }^{21}$.

La crítica más recurrente que se le hace a este tipo de interpretaciones es que no se trató de un nacionalismo agresivo de intenciones expansivas, como el caso italiano y el alemán. Pero la principal objeción que se le efectúa es que analizan al peronismo desde una perspectiva eurocéntrica, como dice Ricardo Del Barco, "no creemos que esta interpretación sea adecuada, en la medida en que no permite la comprensión "desde dentro» del fenómeno»22. Ahora bien, dejando de lado a José Miguens, que señala las que él considera como diferencias entre el fascismo y el peronismo, el resto de autores sólo reivindican la necesidad de desentrañarlo desde parámetros argentinos o latinoamericanos, deslegitimando interpretaciones conceptuales por el solo hecho de haber surgido en otros países. Cristian Buchrucker lo entiende de esta manera y señala que en lo que se refiere a concentración del poder político y organización económica, el régimen era de centro-izquierda, mientras si se toma en cuenta su posición cultural, se ubica más hacia la derecha. Afirma que aquellos que lo inscriben como una forma de fascismo son anacrónicos y "sólo se explica como producto de la pasión politica» ${ }^{23}$.

\section{Visión autoritaria}

Una de las explicaciones predominantes del peronismo lo concibe como autoritario, siendo Luis Alberto Romero y Gino Germani los estudiosos más destacados en la defensa de esta tesis. El primero, al tiempo que admite la influencia de los fascismos, afirma que "Paradójicamente, un gobierno surgido de una de las escasas elecciones inobjetables que hubo en el país, recorrió con decisión el camino hacia el autoritarismo» ${ }^{24}$. Para alcanzar tal objetivo, el prestigioso historiador indica diversos mecanismos de los que se valió Perón: intervenir las provincias con gobiernos disidentes, reemplazar a la Corte Suprema de Justicia mediante juicio político, la ley que puso fin a la autonomía universitaria en 1947; el vaciamiento del contenido real ejercido sobre el Poder Legislativo al elaborarse los

20. Ibidem, p. 159.

21. ROMERO, José Luis, Las ideas políticas en Argentina, Buenos Aires, FCE, 1956, p. 254.

22. DeL BARCO, Ricardo, El régimen peronista: 1946-1955..., p. 19.

23. BUCHRUCKER, Cristian, "Unidad y diversidad en las corrientes internas del justicialismo", en Miguens, José Enrique y TuRner, Frederick C., Racionalidad del peronismo, Buenos Aires, Planeta, 1988, pp. 53-82, p. 77.

24. ROMERO, Luis Alberto, Breve historia contemporánea de la Argentina, Buenos Aires, FCE, 1996, p. 151. 
proyectos en la presidencia, al acusar a los opositores por desacato, excluirlos o desaforarlos, y la modificación del sistema de circunscripciones electorales que redujo la representación electoral de la oposición. Otro dispositivo fue el control de los medios masivos de comunicación a través de la Secretaría de Prensa y Difusión, que le permitió al Gobierno formar una cadena de prensa y radio totalmente adicta. Asimismo, los periódicos fueron presionados a través de cuotas de papel, restricciones a la circulación, clausuras temporarias, atentados e, incluso, la expropiación. Por otro lado, la reforma constitucional de 1949, permitió aumentar y concentrar las atribuciones del Poder Ejecutivo y su reelección. Romero también distingue dos importantes métodos de control: el uso de la autoridad del Estado para disciplinar la sociedad, recurso que había sido empleado por gobiernos anteriores, y el liderazgo personal e intransferible que es alimentado por la maquinaria estatal, y que queda totalmente evidenciado en la renuncia en blanco que debían firmar los futuros diputados antes de asumir el cargo, en el culto al líder y en la verticalidad del Partido Peronista, concebido como una copia del partido alemán ${ }^{25}$. Por último, el autor señala la síntesis entre movimiento y nación, de forma tal que la Doctrina Peronista se transformó en la Doctrina Nacional, anulando la participación de los disidentes.

Según Romero, "los conceptos más tradicionales de democracia no alcanzan a dar cuenta de esta forma, muy moderna, de democracia de masas» ${ }^{26}$, constituida desde el Estado y sustentada en las masas, no en los individuos, entendido como un todo indiferenciado que debía ser moldeado por la doctrina. En esa tarea, las instituciones se convirtieron en instrumentos de peronización. Mariano Plotkin ${ }^{27}$ continúa esta línea de análisis, realizando un muy interesante estudio sobre los mecanismos generadores de consenso político y movilización masiva elaborados por el régimen peronista. Sostiene que esos mecanismos, en un régimen totalitario como el peronista, fueron acompañados de medidas represivas y de exclusión de todos aquellos que no se adhirieron al movimiento. La creación de mitos, símbolos y rituales adquirió un papel fundamental en el imaginario político peronista, destinado a ocupar la totalidad del imaginario público, en otras palabras, a la obtención de lealtades completamente subordinadas a la figura de Perón. Romero agrega el control de las movilizaciones y concentraciones populares como el 1 de mayo y el 17 de octubre, empleadas deliberadamente para ratificar las decisiones políticas; y la legitimación plebiscitaria, que adquirió mayor importancia que las elecciones. En este punto, el trabajo de Eduardo Elena nos ofrece un claro ejemplo, cuando Perón pide a la ciudadanía sugerencias para el Segundo Plan Quinquenal, inaugurando una nueva relación entre planificación y participación. Así, los ciudadanos se sintieron como aliados de un programa económico que les mejoraría sus condiciones de vida, al tiempo que les ofrecía una nueva forma de comunicación con el poder ejecutivo y los

25. «Se trataba de una versión local del célebre Führer prinzip alemán, pero su aplicación fue menos dramática", Ibidem, p. 152.

26. Ibidem, p. 154.

27. PlotKIn, Mariano, Mañana es San Perón, Ariel, Buenos Aires, 1994. 
imbuía en un ideal de modernización, el cual sería construido por el Estado a través de obras públicas y estas nuevas formas de intervención. De esta forma, "Peronist participation built upon classic liberal forms (such as elections), while creating additional venues for interaction between state authorities and the public» ${ }^{28}$.

En esta misma línea tenemos al historiador alemán Peter Waldman ${ }^{29}$, quien aplica el esquema de crisis nacionales de Almond y Pye. Según Waldman, la meta de Perón consistió en que el Estado debía actuar como factor de equilibrio en la sociedad y orientar los procesos políticos, económicos y sociales; objetivos que serían alcanzados siguiendo cuatro principios políticos: compromiso de solidaridad como elemento aglutinador de los individuos, la idea de líder, el principio de organización corporativista o la denominada "comunidad organizada", y el principio de representación. Al señalar las características del estilo de gobierno y las técnicas de dominación peronista, advierte en primer lugar el burocratismo, aumentar las competencias y actividades del Estado, transformándolo en un sobredimensionado aparato que se tornó lento, oneroso e ineficiente, y aplicándole una organización piramidal, que concentraba la toma de decisiones y el poder en el ejecutivo. En segundo lugar, el estilo de conducción autoritaria-plebiscitaria, que define distintos roles para Perón y $\mathrm{Eva}^{30}$, convirtiendo a Perón en la encarnación del principio autoritario mientras Eva representaba la toma de posición del Gobierno a favor de las clases trabajadoras $^{31}$. En tercer lugar, tenemos la técnica de la inconsecuencia, que explica los cambios de rumbo del Gobierno y que le permitía al líder aglutinar el favor de grupos dispares sin la necesidad de quedar atado a uno de ellos. Por último, el culto a la personalidad, característica ya mencionada anteriormente, para la cual se valió del aparato propagandístico oficial, obteniendo muy buenos resultados entre los estratos bajos. Aunque la tesis de Waldman es mucho más amplia, sólo mencionamos aquí aquellos aspectos que contribuyen en mayor medida a nuestros intereses.

\section{Visión populista}

El otro importante estudioso que transita por esta vía interpretativa es el sociólogo Gino Germani, quien sostiene que el líder convierte a las masas en un ente manipulable, fundamento de su poder, sustentado en la ilusión que poseen de participación política ${ }^{32}$. Así, los apoyos sociales al peronismo resul-

28. ELENA, Eduardo, «What people want: state planning and political participation in peronist Argentina, 1946-1955", Journal of Latin American Studies, vol. 37, parte I, febrero 2005, p. 106.

29. Waldman, Peter, El peronismo 1943-1955, Buenos Aires, Hispamérica, 1981.

30. Para un estudio más profundo de la división de roles del matrimonio Perón, LomBILLE, Ramón J., Eva, la predestinada. Alucinante historia de éxitos y frustraciones, Buenos Aires, Gure, 1956.

31. Ibidem, p. 117.

32. "La diferencia entre la democracia y las formas totalitarias, reside justamente en el hecho de que, mientras la primera intenta fundarse sobre una participación genuina, el totalitarismo (...) crea la ilusión en las masas de que ahora son ellas el elemento decisivo, el sujeto activo, en la dirección de la cosa pública", en Germani, Gino, Politica y sociedad en una época de transición, Buenos Aires, Paidós, 1962, p. 335. 
tan primordiales para comprender la naturaleza del mismo: la tesis tradicional afirma a los sectores obreros urbanos como el núcleo central del movimiento, tesis refutada por Peter Smith, historiador estadounidense que concibe a Perón como líder de una frágil alianza con sectores sociales heterogéneos, derivado de la propia complejidad socio-económica y política argentina ${ }^{33}$. No niega el autor la tesis de Germani, pero plantea su parcialidad, considerando fundamental tener en cuenta el apoyo con el que contó el peronismo tanto de sectores urbanos como campesinos, industriales y rurales, de buena parte de los sectores populares, medios y altos. Según Smith, la gran cantidad de apoyos debe buscarse en la forma en que se presentó el peronismo, "como un movimiento de protesta contra el modelo argentino de modernización», causa que aglutinaba a diversos sectores. Por lo tanto, el autor concluye que "Perón conducía una alianza frágil, no una clase monolítica ni un movimiento de masas".

Ahora bien, Germani ${ }^{34}$ afirma que el principal apoyo a Perón provino de los nuevos sectores industriales, emigrados rurales que se ven obligados a trasladarse a las grandes ciudades, a Buenos Aires, Córdoba y Rosario principalmente, como consecuencia del crecimiento industrial resultante de la sustitución de importaciones ${ }^{35}$, que permitió el afianzamiento de industriales nacionales al no tener un mercado competitivo. Así, al finalizar la década de 1930, nos encontramos ante la disponibilidad de líder y de masas; masas que carecían de tradición política y con costumbres correspondientes a la cultura rural, es decir, habituados a una forma de hacer política caudillista y paternalista, y que fueron manipuladas por las precarias condiciones económicas en que se hallaban y por la promesa de participación en la toma de decisiones políticas. Así, el peronismo se convierte en un movimiento homogéneo, integrado por obreros, empleados y vendedores; y que merced a la alianza entre obreros y los nuevos empresarios industriales, se vuelve un movimiento nacional y popular.

$\mathrm{Al}$ igual que Germani, Samuel Baily ${ }^{36}$ afirma que Perón estableció un régimen autoritario antiliberal, sustentado en valores hispano-criollos. Bajo este marco conceptual, el autor señala dos métodos que empleó Perón para destruir la independencia del movimiento obrero: por un lado, hizo que los trabajadores dependieran de él mismo y, posteriormente, del Estado, para el mejoramiento de su condición social y económica; al tiempo que transformó cualquier tipo de conflicto en una cuestión de lealtad nacional.

33. "Perón estaba llevando a la práctica la visión corporativista de los años treinta del general Uriburu, pero con una diferencia vital: hizo de los trabajadores urbanos sus aliados politicos más importantes, flanqueados por los industriales y fuerzas armadas (...) Perón creó una alianza política sin precedentes en la historia argentina: un sindicato de trabajadores, empresarios y militares», en SKIDMORE, Thomas y $\mathrm{SMITH}$, Peter, Historia Contemporánea de América Latina: América Latina en el siglo XX, Barcelona, Crítica, 1996, p. 100.

34. GERMANI, Gino, «El surgimiento del peronismo: el rol de los obreros y de los migrantes internos", Desarrollo Económico, vol. 13, n. ${ }^{\circ}$ 51, octubre-diciembre 1973, pp. 435-488.

35. SCHVARZER, Jorge, La industria que supimos conseguir, Planeta, Buenos Aires, 1996.

36. BAILY, Samuel, Movimiento obrero, nacionalismo y política en la Argentina, Buenos Aires, Paidós, 1984. 
Torcuato Di Tella, emigrado italiano que fundó el Instituto que lleva su nombre, continuó los planteos de Germani, analizando la génesis y permanencia del peronismo. Entre sus miembros señala a los nacionalistas, un grupo de industriales y a los obreros. Los primeros fueron la elite política que lo inició, militares que admiraban a Hitler y al modelo corporativo de Mussolini, de ideología nacionalista, germanófilos durante la guerra y vinculados a la Iglesia. A ellos se agregaron los industriales que se habían enriquecido rápidamente en la década anterior, y que veían en el conflicto armado peligrar sus intereses, al no estar protegidos por el Estado nacional, que volvería a privilegiar la producción de materias primas para exportar e importaría los bienes manufacturados de las enclenques fábricas europeas. "La vinculación que hubo entre sus intereses de militarismo hegemónico y expansionista, y los de este grupo industrial, que necesitaba de protección aduanera como cuestión de vida o muerte» ${ }^{37}$ se estrecha aún más cuando entre las industrias que peligraban si se volvía al modelo agro-exportador anterior tenemos a la empresa armamentista, dependiente a su vez de la industria pesada, ambas en manos militares. Es, teniendo en cuenta todo ello, que se comprende el Primer Plan Quinquenal. A estos sectores se incorporó la clase obrera de forma bonapartista, es decir, actuando de forma pasiva y «los intereses que van a ser defendidos por ella son los de los sectores altos de la sociedad, y no los de la masa obrera y campesina ${ }^{38}$; allí radica el motivo por el cual el peronismo no es un movimiento de masas. Al elemento bonapartista, Di Tella agrega, como característica del movimiento obrero, el espontaneísmo: a la estructura sindical impuesta como medio para resolver los conflictos laborales y a las distintas formas en que el poder ejecutivo apeló para mantener entre determinados cauces a los trabajadores, se debe sumar el accionar de algunos líderes obreros que buscaron soluciones rápidas a sus problemas y llevaron a cabo acciones inmediatas para conseguirlo. Se trató de líderes ocasionales, de acciones reducidas en el tiempo y de un sector minoritario dentro del grupo obrero.

Frente a las masas disponibles de Germani, Murmis y Portantiero ${ }^{39}$ sostienen que el acelerado crecimiento industrial de la década de 1930 condujo a una política de reagrupamiento de las fuerzas sociales y, finalmente, a una alianza de los sectores propietarios, de forma tal que no habrá oposición entre terratenientes y burguesía industrial por cuanto compartían el interés en una industrialización limitada. Así, grandes industriales y hacendados invernadores también brindaron su apoyo al régimen. Señalan los autores, que en la búsqueda de Perón por conquistar a los industriales, recurrió en sus discursos a reiterar e inflar el peligro comunista: ante la amenaza anárquica o comunista, el dirigente propuso la organización de sindicatos, tanto de trabajadores como de empresarios, mediante los cuales canalizar y solucionar los conflictos laborales.

37. Di TeLLA, Torcuato S., El sistema politico argentino y la clase obrera, Buenos Aires, EUDEBA, 1964, p. 56.

38. Ibidem, p. 57.

39. Murmis, Miguel y PORTANTIERO, Juan Carlos, Estudios sobre el origen del peronismo, Buenos Aires, Siglo XXI, 1971. 
La hipótesis de Germani también es cuestionada por Daniel James ${ }^{40}$, quien afirma que Perón construyó la clase obrera, dando lugar a la formación de una moderna clase trabajadora. Entiende que la atracción por los beneficios socioeconómicos resultó fundamental en el proceso de integración de esa fuerza social a la coalición política emergente, situación que se profundizó una vez Perón asumió el poder ejecutivo. A esos beneficios debe añadirse la retórica peronista, su carácter creíble y concreto, que alentaba el corporativismo como medio para defender sus intereses, apuntalaba a Perón como vocero de la clase obrera, a la cual se la hizo depositaria de los valores nacionales, y la denuncia de un sistema democrático tramposo, con escaso contenido democrático real. A los beneficios socio-económicos y el discurso pragmático, debe sumarse el carisma de Perón y un eficiente aparato propagandístico estatal, todo lo cual explica, según James, el éxito alcanzado por el peronismo entre las clases populares.

$\mathrm{Al}$ ampliar la base de apoyo del peronismo, ya sea confluyendo nuevos y viejos obreros como incorporando a industriales o hacendados, se convierte en un movimiento populista, tal y como lo entienden los autores citados anteriormente. Juan Carlos Torre ${ }^{41}$ continúa este camino, afirmando que el surgimiento del sindicalismo de masas nos remite a un momento de crisis y reorganización del Estado en el que surge una nueva elite dirigente militar que procura darse una base de apoyo social apelando a la movilización de los sectores populares. La influencia sindical reducida a los viejos obreros, la exclusión política y la centralidad económica, otorgaron fuerza al movimiento obrero y popular, que buscaba reposicionarse frente a los que conducían el desarrollo económico. Es aquí donde aparece la figura de Perón como árbitro entre los grupos populares y los conservadores y miembros de clase media que miran el ingreso de los primeros en el ámbito político con recelo. Siguiendo a Torre, Perón, y una vez electo presidente, el régimen peronista, llevó adelante un proceso de democratización por vía autoritaria, mediante el cual otorgó sustanciales mejoras a los obreros. La dependencia que Perón tenía en relación al movimiento obrero, lo lleva a renegociar constantemente su hegemonía, para lo cual recrea constantemente las condiciones de origen.

León Rozitchner aplica la teoría psicoanalítica a la relación entre la clase obrera y Perón, llegando a interesantes observaciones. Señala que mientras Perón se ubicó como dominador, la clase obrera se mantuvo en un lugar de dependencia y sumisión, «llenando un vacio, al padre que perdona, que le da por amor (...) con una sola condición: que no lo quieran más que a él» ${ }^{42}$. Ese amor se hace evidente en los beneficios laborales y económicos que otorga, empirismo también preeminente en el desprecio por la razón, incomprensible para las masas. Así,

40. JAMES, Daniel, Resistencia e integración. El peronismo y la clase trabajadora argentina, 1946-1976, Buenos Aires, Sudamericana, 1990.

41. TORRe, Juan Carlos, La vieja guardia sindical y Perón. Sobre los orígenes del peronismo, Buenos Aires, Sudamericana, 1990.

42. ROZITCHner, León, Perón: entre la sangre y el tiempo. Lo inconsciente y la política, Buenos Aires, CEAL, 1985, p. 259. 
Perón intentó "articular dos sistemas: el subjetivo, que conforma a cada peronista, con el objetivo del sistema de producción» ${ }^{43}$; alcanzando la dominación total de los obreros, en cuerpo y alma, de forma tal que las concesiones otorgadas a los sectores populares no eran conquistadas sino fruto de la generosidad del padre. Asimismo, Perón los convence de que obtienen sin dar nada a cambio, despojando a la "clase obrera de su propio discurso y de su voz» ${ }^{44}$. Rozitchner concluye: "esa guerra contra la clase obrera fue el militar Perón quien la ganón ${ }^{45}$; los sectores populares fueron despojados de todo, se les impuso una determinada identidad y tomaron como propia una causa que brinda mayores beneficios a sus adversarios.

Como hemos podido observar, el peronismo entendido como populista o como forma de nacionalismo popular tiene su fundamento en los apoyos que lo sostuvieron en el poder y en los textos y discursos del propio Juan Domingo Perón. Entre ellos, podemos señalar parte de la disertación que el General leyó a la Asamblea Constituyente Reformadora el 27 de enero de 1949, cuando afirma como fundamento de su Gobierno la voluntad popular: «El clamor popular que acompañó serenamente a las fuerzas armadas el 4 de junio y estalló pujante el 17 de octubre, se impuso, solemne, el 24 de febrero» ${ }^{46}$. Es durante el propio Gobierno peronista que la interpretación populista surge de mano de los revisionistas rosistas y peronistas, quienes intentaron conquistar el espacio público, objetivo que no lograron conseguir merced a la amplitud de procedencias ideológicas que sostenían al régimen. Sólo cabe recordar los nombres de próceres liberales que el régimen peronista otorgó a todo aquello que inauguró: desde estaciones de tren, escuelas, hospitales, entre otros. Ahora bien, una vez derrocado el Gobierno, su visión del pasado comenzó a tener cada vez mayor difusión, desempeñando un papel fundamental en el período formativo de la futura juventud peronista ${ }^{47}$. Al comparar la figura de Rosas con la de Perón, defendieron que se trataba de dos líderes carismáticos y fuertes, que se levantaron para defender a las masas despojadas por las elites dirigentes del país. Con la Revolución Libertadora, encontraron una nueva similitud: ambos debieron exiliarse como consecuencia de movimientos antidemocráticos. Aquí encontramos a Eduardo Duhalde, José María Rosa y John William Cooke, que sostuvieron a Perón como defensor de los valores e intereses nacionales y enfrentándose a las grandes potencias. Co-

43. Ibidem, p. 263.

44. Ibidem, p. 338.

45. Ibidem, p. 339.

46. Perón, Juan Domingo, "Discurso del General Perón al iniciar las sesiones de la Convención Nacional Constituyente", Cuadernos del Instituto Nacional Juan Domingo Perón, n. ${ }^{\circ}$ 7, p. 4. http:// www.jdperon.gov.ar/cuadernos.htm (22-04-2007). En un folleto editado poco después del 17 de octubre de 1945 y reproducido por el mismo Instituto, el coronel, que había firmado bajo seudónimo, afirma: "Yo personalmente me acerqué siempre a las masas obreras, que reconozco han sido mi predilección, porque ellas representan el dolor y el sudor de la Patria...", en CALEDONIA, Bill de, «¿Dónde estuvo? Relatos históricos del 17 de octubre de 1945», Cuadernos del Instituto Nacional Juan Domingo Perón, n. ${ }^{\circ}$ 4, p. 5.

47. Feinmann, "Política y verdad. La constructividad del poder», en Sosnowski, Saúl (comp.), Represión y reconstrucción de una cultura: el caso argentino, Buenos Aires, Eudeba, 1988, pp. 79-94, p. 85 . 
oke va más allá, concibiendo al peronismo como el movimiento que guía a las masas en el proceso revolucionario, revolución social y anti-imperialista, que es entendida como "comunismo o castrocomunismo para un régimen que no comprende que castrismo, peronismo, brizolismo, caamañismo, etc., son las formas nacionales que toma un mismo proceso de dimensiones latinoamericanas y universales» ${ }^{48}$. Recordemos que su libro, de vocabulario combativo y ausencia total de estilo académico, fue escrito hacia 1965, a diez años del golpe de Estado que derrocó a Perón.

Si al apoyo popular sumamos la ideología nacionalista, llegamos a la conceptualización del peronismo como populista nacionalista. En este marco, se concibe a Perón como heredero de la tradición federalista del siglo XIX y defensor de los intereses nacionales frente a los extranjeros o elitistas. Esta concepción es la que defiende Ricardo Del Barco, historiador que distingue dos tradiciones sociales en la historia argentina: la liberal y la populista, escisión que conduce a una profunda crisis de legitimidad del sistema político argentino, que se ve imposibilitado de articular un régimen que compatibilice la participación, el desarrollo y la democracia, y de la cual surgirá el peronismo. Según el historiador, el populismo "pretende tener sus raíces en lo hispano-criollo, reivindica un sentir democrático, con desapego hacia las formas institucionales y reivindica más bien un sentido gregario del pueblo. Pone el acento en el pueblo, desde el cual mira a la sociedad, que queda bajo la mirada vigilante del primero. La libertad civil es renegada, la libertad política retaceada y el pluralismo social es parcialmente adoptado»49. De tal forma, al mismo tiempo que señala la base popular, también distingue sus deficiencias en cuanto a la libertad y al pluralismo político, en tanto una vez en el poder, Perón estructuró un régimen de partido dominante en el cual no se permitió el disenso. Pluralismo también limitado al convertir la doctrina peronista en Doctrina Nacional.

El partido peronista, que nace como Partido Único de la Revolución Nacional, una vez ganadas las elecciones presidenciales ${ }^{50}$ se presenta con una estructura partidaria única, organizado en tres niveles: la junta ejecutiva nacional, la dirección provincial y la dirección municipal. Así, una estructura piramidal, le permitía al Gobierno alcanzar la totalidad de la geografía argentina, desdibujando el límite entre Gobierno y partido; al tiempo que sostenía a Perón como árbitro en los conflictos partidarios y nacionales. Siguiendo esta línea de análisis, Alberto Ciria ${ }^{51}$ retoma las características esbozadas por Little y se las atribuye al Partido Peronista: carácter monolítico derivado de la escasa tolerancia, cuando no supresión, de las facciones disidentes; la naturaleza policlasista de sus apoyos y el carácter personalista y autoritario. La tensión entre retórica y realidad acentuó la burocratización y dependencia del Partido Peronista respecto del poder ejecutivo, al tiempo que condujo a Perón a insistir en la organización de las

48. CoOKE, John William, Peronismo y revolución. Informe a las bases, Buenos Aires, Granica, 1973, p. 216 y ss.

49. Del BARCo, Ricardo, El régimen peronista 1946-1955..., pp. 160 y ss.

50. Ibidem, pp. 47 y ss.

51. Ibidem, pp. 37 y ss. 
fuerzas a nivel gremial y político. Así, Perón se erige en conductor del desorden, privilegiando una organización y conducción centralizadas en su persona. De esta manera, tanto Ciria como Del Barco, coinciden en afirmar a un Perón que al llegar al poder estructura un régimen de partido dominante donde el disenso es claramente censurado. Por el contrario, Moira MacKinnon ${ }^{52}$, presenta a un Partido Peronista donde anidan incesantes conflictos derivados de la propia heterogeneidad del movimiento. Heterogeneidad que encuentra su raíz en los diversos grupos que lo integran: derivada del origen, con el Partido Laborista apoyado por las clases populares y la Junta Renovadora por los sectores medios, y de la experiencia, donde los laboristas representan una fuerza nueva frente al know how de la Junta Renovadora. De esta manera, la autora nos presenta a un partido que no actúa como agencia del poder estatal, que no representó la voluntad de Perón y que tuvo una gran vitalidad, resultado de los debates y las luchas políticas internas.

En el proceso de organización de las masas, de creación de la "comunidad organizada", lo que le imprime un rumbo es la ideología. Siguiendo a Ricardo Del Barco ${ }^{53}$, la doctrina peronista se cimentó en tres ideas fuerza: la justicia social, la independencia económica y la soberanía política. La primera es llevada a cabo por el Estado a través de medidas redistributivas y la conducción de los conflictos sociales. Por la segunda, el Estado argentino no depende de otros países o grupos económicos, siendo autosuficiente para su desarrollo económico. Por la última, Perón se asume como voluntad del pueblo. La noción de equilibrio es de suma importancia, en tanto es la que rige la concepción peronista de comunidad organizada, la "Tercera Posición", y el rol del Estado. Comunidad organizada entre espíritu y materia, individuo y colectivo, egoísmo y solidaridad; "Tercera Posición» entre la política individualista capitalista y el marxismo internacionalista; y un Estado con dos funciones claramente definidas: como árbitro entre trabajo y capital y como artífice que debe hacer efectiva la justicia social mediante los sindicatos. Ya en la campaña electoral de 1946, la justicia social fue empleada como lema por el Partido Laborista, mientras sus contrincantes, la Unión Democrática, enarbolaban la libertad. En esas elecciones de 1946 se enfrentaron dos estilos de democracia distintos: uno liberal encarnado en la Unión Democrática, y otro democrático-igualitario que sostenía una libertad política reducida.

En líneas generales, Cristian Buchrucker ${ }^{54}$ coincide con Del Barco, aunque su trabajo es de mayor profundidad y análisis. A lo que el segundo denomina ideas fuerza, el primero las llama principios. A la justicia social, la independencia económica y la soberanía popular, Buchrucker agrega la democracia social, que reemplaza a la democracia liberal anterior, lo cual era posible previa instauración de la soberanía política que se expresó en la libre determinación

52. MACKInNon, Moira, Los años formativos del partido peronista, Buenos Aires, Siglo XXI, 2002.

53. DEL BARCO, Ricardo, El régimen peronista 1946-1955..., pp. 61 y ss.

54. BuCHRUCKer, Cristian, Nacionalismo y peronismo. Argentina en la crisis ideológica mundial (19271955), Buenos Aires, Sudamericana, 1987. 
de los pueblos en el ámbito internacional y en la supremacía de las decisiones mayoritarias en el plano político interno; y la comunidad organizada, entendida como todas aquellas asociaciones englobadas bajo el concepto de la solidaridad. El autor va más allá y plantea una serie de elementos constitutivos de la doctrina peronista, distinguiendo en primer lugar, el nacionalismo, influenciado por la corriente populista, aunque también compartía elementos con el nacionalismo restaurador ${ }^{55}$. Del primero tomó el empirismo, la fe en el pueblo, la postura antioligárquica y anti-imperialista; del segundo, el modelo económico nacionalista y dirigista. Otros elementos eran: el catolicismo social, influenciado por la doctrina social de la Iglesia; de los modelos militares tomó la concepción organicista; los modelos hispanoamericanos de Vargas en Brasil (1930-1945), Lázaro Cárdenas en México (1936-1940) y Toro y Busch en Bolivia (1936-1939); los modelos europeos fascista y nazi, y sus logros técnicos y organizativos en lo económico y social; y, por último, el fruto de su experiencia, en la Secretaría de Trabajo y Previsión, y del conflicto con el embajador estadounidense Braden.

David Rock ${ }^{56}$, al igual que Del Barco, entiende el fenómeno peronista como una forma de populismo, resaltando los mecanismos manipuladores empleados por su jefe en la conducción de las masas. Le reconoce a Perón influencia de las doctrinas corporativistas, por las cuales la justicia social y los sindicatos pasaban a un primer plano, siendo controlados por el Estado; corporativismo que iba acompañado de ideas nacionalistas. En una obra posterior, donde estudia el devenir histórico de los nacionalistas, agrega que el Gobierno peronista llevó adelante un viraje hacia 1948, transformándose en una dictadura ${ }^{57}$, señalando sus orígenes antidemocráticos y las influencias de otros regímenes autoritarios en el pensamiento y accionar peronista ${ }^{58}$.

\section{Visión socialista}

En contraposición a esta forma de interpretar el peronismo, también fue entendido como un estadio en el camino hacia el socialismo. Bajo esta interpretación, el peronismo se convierte en un movimiento de liberación policlasista, que conduciría irremediablemente hacia un socialismo nacionalista. Esta concepción surgió con posterioridad a la Revolución Libertadora, de mano de peronistas seducidos por el contenido social del discurso del General, siendo dejada de lado posteriormente, debido fundamentalmente a lo sucedido a partir

55. Para nacionalismo restaurador y nacionalismo populista véase DEVOTO, Fernando y BARBERO, María Inés, Los nacionalistas, Buenos Aires, CEAL, 1983.

56. RoCK, David, Argentina 1816-1987, desde la colonización española hasta Raúl Alfonsín, Madrid, Alianza, 1988, p. 327.

57. Rock, David, La Argentina autoritaria. Los nacionalistas, su historia y su influencia en la vida pública, Buenos Aires, Ariel, 1993, pp. 168 y ss.

58. "A fines de 1948, ya en el ocaso de la euforia de posguerra y en el marco de un malestar creciente, comenzó a abandonar lo que él denominaba "los métodos genéricos de la democracia" y a instaurar una dictadura. Ello se tornó visible cuando el régimen empezó a enfatizar su doctrina nacional o "Justicialismo»", op. cit., p. 171. 
del retorno de Perón al país. En esta línea encontramos a Hernández Arregui ${ }^{59}$, quien entendía que las reformas sociales peronistas y el apoyo que las masas profesaban al líder peronista, conducirían a una superación de manera natural del régimen, que dejaría de ser un peronismo socialista y se convertiría en un socialismo nacionalista. Por su parte, Rodolfo Puiggrós ${ }^{60}$ asimiló marxismo y nacionalismo, comunismo y peronismo. Sus ideas tuvieron profunda influencia sobre la juventud peronista y la subsiguiente radicalización de estudiantes universitarios y sectores medios de la sociedad durante las décadas de 1960 y 1970. Concibió a la historia argentina como la lucha entre dos corrientes: el liberalismo extranjerizante y el nacionalismo socialista, cuyo primer exponente fue Yrigoyen, pero al ser derrocado, el radicalismo no encontró un interlocutor capaz de continuar ese proceso de reivindicación de lo nativo. En medio de una importante crisis de legitimidad en la que se encontraba sumergido el régimen conservador, Perón se da cuenta de la imposibilidad de gobernar sin el apoyo de las clases populares y el nacionalismo socialista, convirtiéndolos en fundamento de su poder, haciéndose heredero de la tradición caudillista ${ }^{61}$.

\section{CONCLUSIÓN}

Como hemos visto, el peronismo ha sido interpretado fundamentalmente de cuatro formas: como bonapartismo o bismarckismo, nazi-fascista, populista, o como un estadio en el camino hacia el socialismo. Cada una de estas explicaciones depende, más que de privilegiar unas determinadas fuentes o apoyos al régimen, de la adscripción ideológica de cada investigador. Como dice Galasso, "detrás del relato -y aún descartando toda intención engañosa por parte del historiador- está presente su ideología, lo cual colorea a su modo los sucesos relatados, otorgando mayor o menor importancia a cada uno, reconociéndoles perfiles positivos o negativos, ofreciendo unas $u$ otras explicaciones, según su particular óptica» ${ }^{62}$. Al caso peronista debemos agregar su presunción de inclasificable: "habría sido un movimiento único, original, extraordinario, reacio a las clasificaciones y marcos teóricos de las ciencias sociales» ${ }^{63}$. A pesar de todo ello, y como se ha podido comprobar a lo largo del trabajo, las coincidencias entre los investigadores son muchas. Los rasgos autoritarios, el personalismo, el culto al líder, la concepción organicista y

59. Hernández ArRegui, Juan José, Peronismo y socialismo, Buenos Aires, Hachea, 1971. Disponible en: http://www.elortiba.org/herar.html\#PERONISMO_Y_SOCIALISMO_(15-04-2007).

60. PUIGGRós, Rodolfo, El yrigoyenismo, Buenos Aires, Corregidor, 1974; De la colonia a la revolución, Buenos Aires, Leviatán, 1957; Origen y desarrollo del peronismo, Buenos Aires, Misur, 1973; La democracia fraudulenta, Buenos Aires, Corregidor, 1972. Un análisis sobre su obra en TORTORELLA, Roberto Luis, Marxismo, populismo y liberación nacional. La mirada sobre el peronismo de un comunista disidente (Rodolfo Puiggrós, 1954-1959), en: http://historiapolitica.com/datos/biblioteca/tortorella. pdf (18-04.2007).

61. "Con la aparición de Perón, el caudillo sepultado para siempre por la mediocridad liberal resucitaba y se modernizaba en el líder", en PUIGGRós, Rodolfo, El peronismo: sus causas, Buenos Aires, Puntosur, 1988, p. 34.

62. GALASSO, Norberto, La larga lucha de los argentinos..., p. 8.

63. TCACH, César, «El enigma peronista. La lucha por su interpretación»..., p. 129. 
corporativista del Estado y la sociedad, la influencia de los modelos europeos, lo mismo que también se deben reconocer las medidas sociales, la gran habilidad política demostrada por Perón, su pragmatismo y dotes oratorias. Todo esto nos acerca al fascismo de forma evidente, concepto evitado por los historiadores argentinos que continúan elaborando largas y complicadas definiciones y caracterizaciones para comprender el peronismo. Fascismo asociado al populismo, en tanto son las masas el concepto fundamental en la configuración ideológica del régimen, y es el indudable apoyo popular, al menos inicial, el que le permite al coronel llevar a cabo sus aspiraciones políticas.

Si todavía queda alguna duda, sólo hay que dejarlo hablar al General y la interpretación cae por su peso. Recordemos simplemente cuando después del bombardeo a Plaza de Mayo anunció: "Y cuando caiga uno de los nuestros, caerán cinco de ellos». 